\title{
Agency in non-professional manga translation in Iran
}

The International Journal for Translation \& Interpreting Research trans-int.org

\section{Saleh Delforouz Abdolmaleki}

University of Isfahan, Iran

s.delforouz@gmail.com

Mansoor Tavakoli

University of Isfahan, Iran

mr.tavakoli14@gmail.com

\section{Saeed Ketabi}

University of Isfahan, Iran

s.ketabi@yahoo.com

DOI:10.12807/ti.110201.2018.a06

\begin{abstract}
The present study addresses the phenomenon of online nonprofessional translation of manga in the context of Iran from the perspective of agency. It focuses on the people involved in decision-making in nonprofessional translation production, the non-professional translators' motivations for their free immaterial labor as well as the factors that can constrain or increase their willingness or ability to translate manga into Persian. These questions were answered based on the activities of AnimWorld, the largest Iranian community of non-professional translators. The results suggest that non-professional translations differ from professional translations in terms of decision-making processes, motivations of the individuals involved as well as the contexts where they practice.
\end{abstract}

Keywords: agency, context, decision, fan translation, manga, motivation, non-professional translation, online community.

\section{Introduction}

Unlike professional translation, which has traditionally been the focus of translation researchers working on the English-Persian language pair, nonprofessional translation has not yet been recognized as a distinctive phenomenon in the context of Iran. Professional translation refers to translations produced by individuals who "designate themselves as 'translators' or 'interpreters' and are recognized (and paid) as such by their commissioners" (Pérez-González \& Susam-Saraeva, 2012, p.150) while nonprofessional translation refers to the translations undertaken by "individuals not only without formal training in linguistic mediation but also working for free” (Pérez-González \& Susam-Saraeva, 2012, p.151). 
The present study is an attempt to describe and examine non-professional translation in Iran from the perspective of agency. 'Agency' has been defined by Kinnunen \& Koskinen (2010) as a human's "willingness and ability to act". In this definition willingness can be understood as a translator's inclination to translate a work into another language by choice and without reluctance, ability as the presence (or lack) of power in a translator to decide on what and how to translate, and acting can be defined as a translator's exertion of influence in the real world through translation (Kinnunen \& Koskinen, 2010, p.7).

A review of the way Haddadian-Moghaddam (2014) investigates agency in professional translation in Iran can help to further clarify the concept. He proposes a three-tier model in which agency is broken down into the three components of decision, motivation and context. These are then dealt with in turn in an attempt to discover the people who decide what gets translated and the factors that motivate the translators to translate as well as the factors which constrain or increase their agency.

In his diachronic analysis of professional literary translation in Iran during a period starting from the late nineteenth century to modern-day Iran, he investigates decision-making at two levels: decisions made regarding what books/authors get translated as well as those concerned with stylistic preferences and translation strategies. Such decisions, especially during the first two periods under investigation in his study, were made mainly by translators themselves, with publishers playing an important role. In modernday Iran, as far as gatekeepers, or the selectors of works for translation, are concerned, Haddaian-Moghadam suggests that some publishers give preference to "first-class literature" over "second-hand literatures" in their selections of works for translation. He regards this as an attempt to "provide a publishing model that does not rely solely on the discretion of translators" (Haddadian-Moghadam, 2014, p.120).

As for the motivation of professional translators in contemporary Iran, based on the results of his interviews with translators and publishers, Haddadian-Moghadam (2014) concludes that Iranian translators usually have altruistic and non-economic motives for their jobs. He also found that professional translators felt that they provided cultural service to their fellow countrymen by raising their awareness of other cultures. And interestingly, some translators are reported to do their translations for the sake of finding peace and serenity in the troublesome world surrounding them. For instance, Hosseini (1990), the translator of Faulkner, held that sometimes translating books worked for him as "opium to escape from the extreme anxiety of the Iran-Iraq War" (Hosseini, 1990, p.22). Haddadian-Moghadam (2014) reports that he could hardly find monetary remuneration as a motivation among Iranian professional translators.

As for context, or the contextual factors that are believed to limit or boost the agency of translators and publishers, Haddadian-Moghadam (2014) identifies two sublevels: textual and extratextual. This categorization is useful in that it attempts to distinguish factors that arise from the text itself (textual context) as opposed to factors that are present in the social environment wherein a text is translated (extra-textual context). On the textual sublevel, he sees translating names of people, streets, currency, etc. as potentially affecting a professional translator's agency, as trying to find proper equivalents for such terms can take them a long time and may result in being unable to meet a deadline. On the extratextual sublevel, however, he includes censorship as a factor constraining translators' agency in contrast with subsidies and 
competition, which are regarded as boosting factors. Considering the agency of publishers, he sees lack of capital, censorship, and low readership as well as lack of subsidies as influential factors that limit the agency of publishers.

Our focus being on non-professional translation, the present study is an attempt to discover the parties who make decisions regarding what gets translated by non-professionals and how, to discover the incentives that motivate non-professional translators to translate without expecting compensation, and also to analyse the factors arising both from the text (textual) and from outside the text (extra-textual) that act as "constraints or encouragements" affecting a non-professional translator's agency or, as Chesterman (2017) puts it, their "decision to act in a given way" (p.2). In line with Haddadian-Moghadam (2014), the above issues are discussed under the three categories of 'decision', 'motivation' and 'context'.

\section{Agency in non-professional translation outside Iran}

Recent literature on the practice of cultural translation in Iran includes some studies focusing on translations by professionals, with a special attention to the effect of different ideological values dominant in the country before and after the Islamic Revolution (see Rahimi (2015) and Kenevisi \& Sanatifar (2016)). Haddadian-Moghadam's (2014), however, remains one of the few investigations into the sociological aspects of professional translation in Iran, while to the best of our knowledge non-professional translation in Iran has received very little academic attention. That being the case, a review of the three components of agency as observed in the practice of translation by nonIranian non-professional translation communities provides better grounds for understanding this phenomenon in Iran.

\subsection{Decision}

The following two studies describe the status of non-professional translators as decision-makers. Firstly, in a study aiming at "mapping the uncharted territory of non-professional translation", Pérez-González \& Susam-Saraeva (2012), suggest that non-professional translators decide what to translate and how and where to distribute their translations. In that way they take on the role of translation commissioners, which in turn enables them to challenge the overarching dominance of the traditional "capitalist structures" whereby media industries control the distribution and consumption of translations.

Terpstra (2012) compares and contrasts the practices and norms of nonprofessional (fan) translators of manga with those of the American manga publishing industry in the three stages of selection, translation, and distribution. He suggests that unlike the translators who are commissioned by publishing companies, non-professionals do not select the manga they translate based on "what will sell well". Since they are not financially compensated for their labor, it is, instead, their personal preference that determines the works they will translate. As for decisions concerning stylistic preferences and footnotes, Terpstra (2012) argues that non-professional translators "have power that the professional translators do not" (p.102). They are reported to choose their translation strategies according to what they deem to be the best for the manga they are translating rather than "following a publisher's style guide and suppressing one's own translation preferences in order to conform to those of the publisher" (Terpstra, 2012). 


\subsection{Motivation}

The literature is scarce with respect to the motivations of non-professional manga translators. Mesipuu's (2012) is one of the few studies focusing on the incentives of user-translators who voluntarily translate Facebook and Skype. He posits that these translators are motivated by such factors as realizing their potential, learning, productive selfishness, belonging and doing things that matter and ambition in no specific order.

Realizing one's potential means translators have an opportunity to do something different from what they are required to do to make a living. Through translations, non-professionals are given a chance to demonstrate their ability to function as translators who can localize a product, translate a book or subtitle audiovisual material.

Learning occurs when one is working with other translators who have more experience. Taking advantage of the informal mentorships in participatory cultures (Jenkins, 2009), novice translators obtain immaterial compensation for their voluntary translation and consequently make themselves more marketable.

By productive selfishness Mesipuu (2012) refers to a willingness to do a task free of charge either because the users wish to provide a particular feature which is not provided by the producer, such as a user interface for an application in the translators' native language, or to provide a replacement for the low-quality translations already available in their languages. This motivation is selfish since the user "is acting out of personal need" and it is productive because "it creates a cultural artefact that many other people can benefit from" (Mesipuu, 2012, p. 44). Enabling their fellow citizens to use online resources in their own native language as well as being part of the community whose products they translate gave the voluntary translators under study a feeling of belonging and doing things that matter.

Ambition is defined as volunteer translators' desire to make people from their country who are using a foreign material in their native language aware of the fact that they have made it available in that language. This motivation has been described by Howe (2008) as the volunteer translators' sense of ownership rooted in the feeling that they own the contribution they have made. Howe (2008) sees taking part in community meetings, where nonprofessional fan-translators have a chance to see other like-minded members as well as the managers of their community, as another source of motivation.

\subsection{Context}

In recent years scholars such as Díaz-Cintas \& Muñoz Sánchez (2006) and Dwyer (2012) have discussed the practice of non-professional translation in general. However, there has been no corresponding interest in the context, or textual and extratextual circumstances. This is especially true for one of the most productive areas of non-professional translation, which is the translation of manga and animes produced by online communities.

In one of the few studies in the field, Terpstra (2012) compares the activities of non-professional American translators of Japanese manga with those of professional translators employed by manga-publishing industry in the U.S. Concerning the textual factors affecting non-professional translators, he observes that many professional translators try to avoid using cultural notes in order to produce a "fluid, readable manuscript approximating the original experience of reading the source text" (p. 113). Conversely, non-professionals hold that "there must be some kind of co-text or meta-text to convey the original meaning to readers in the most "literal" way possible (p. 115). Non- 
professional translators convey "original meaning and the author's intentions of the source text" as well as "the good experience of the original version" (p. 115 ) to their readers by translating cultural terms by extensive use of cultural notes. This is in contrast to the professional translators' view that a translation must read as fluent as the original and that the translator needs to be as invisible as possible by avoiding the use of cultural or other kinds of notes.

Zhang \& Mao (2013) have identified extra-textual factors that shape the environment wherein Chinese non-professional translators operate. The first one is the availability of Internet technologies that grant translators access to materials not provided by the official Chinese outlets or which are banned by the State. This is coupled with a fairly tolerant attitude of the Chinese government towards the products of non-professional or fan translators compared to those produced through official venues. Copyright is another factor moulding the extratextual sphere of non-professional translation in China. The non-professional translation communities and the translators contributing to them are at great risk if the government decides to enforce copyright rules in the country. Also Chen (2014) reports that the website where YYeTs, one of the largest groups of fansubs (subtitles produced by fans) in China, published its subtitles for American TV series was suspended and its servers blocked when they were charged with copyright infringement. Commercialization is another force that plays a major role in the extratextual context of non-professional translation in China, for example, when some forces try to appropriate and sell what non-professionals are offering their consumers for free. Another extra-textual factor, which acts as a constant challenge to Chinese fan translators is censorship. They consciously refuse to deal with objects that are evidently political. This is because it is believed that the Chinese government is carefully monitoring the political activities of its citizens (Zhang \& Mao, 2013).

\section{Agency in non-professional translation in Iran}

In the previous section, decision, motivation and context were described as the three components of agency in professional translation in Iran and nonprofessional translation in some other countries under the broader concept of agency. In this section examples illustrating each of these components are provided. The examples are drawn from the products of AnimWorld, the Iranian non-professional translation community. This community, which is primarily active in translating manga from English into Persian, was selected because it is the oldest and the most productive community of nonprofessional translators in Iran. All mangas analyzed in the present study are translated by this community.

Manga or Japanese comics were probably first created in the $12^{\text {th }}$ century (Akiyama, 1990), though the name 'manga' itself began to be used much later. Like comic books, manga are made up of the four elements of pictures, words, balloons and panels. Pictures are used to depict objects and figures, words (including onomatopoeias) indicate what the characters say audibly or what they think of (in their minds). Balloons are used to contain audible speech and thought with different shapes indicative of each type. Panels act as containers of both pictures and words as well as the integrators of time and space (Masami, 2001). They are, however, different from Western comics in a number of ways. The most important difference is that "manga focuses on one main character. The reader follows in the footsteps of that character and sees 
everything through the character's eyes" (Cha, 2007). Being in Japanese, manga are read from right to left and back to front. They are in black and white and, in contrast with Western comics, are most popular with male readers (Jüngst, 2015). Johnson-Woods (2010) identifies different manga genres, appealing to different age groups and various interests, namely shonen (boys' manga), shojo (girls' manga), seinen manga (men's manga) and josei manga (women's manga) as well as such subjects as "humor, religion and spirituality, and war" (p. 9).

Since comics started to be read in Iran before manga and paying heed to Johnson-Woods' (2010) description of manga as adding "yet another layer to the long and complicated evolution of comics", it is appropriate to first analyze the status of comics (including comic strips and comic books ${ }^{\mathrm{i}}$ ) in Iran. The earliest cases of comics published in Iran have been traced back to the early 1950s, when translated American and British comic strips started to appear in popular children's magazines (Tarhandeh, 2011). Around the same time the first Iranian comic strips appeared in children's magazines. They usually narrated Iranian folk tales or legends. One of the most prominent ones was the life story of Shah Abbās I in the children edition of Tehran Mosavvar Magazine in 1957. In the early 1970s The Adventures of Tintin started to appear in the market as the first comic books published in Iran. They were based on English translations of the series, which were originally in French (indirect translation). However, the first Iranian comic book, the Story of Rostam and Esfandīär, was created by Siroos Rad in 1976. Following the Islamic Revolution in 1979, the strong anti-West attitude among politicians and some artists contributed to comics being regarded as superficial literature aiming at propagating Western culture by means of Western superheroes Therefore, comic books were unofficially banned from publication in the late 1980 s, but comic strips in magazines and newspapers continued to be tolerated (Tarhandeh, 2011). While comic books were still frowned upon by the cultural authorities, Ahmad Arablou published The Adventures of Amin and Akram in 1992. It was followed by two other comic books dealing with the Iran-Iraq war and the battle of Ashura in 1997 and 2009 respectively (Tarhandeh, 2011).

Nowadays comic strips are frequently found in Iranian newspapers and magazines, although there is still a negative attitude towards comic books. As Gharibpour (2016) puts it "It's ironic that I always hear publishers saying that in Iran no comic book could be successful except the Tintin!" He believes the reason is the professional artists" view of comic books as "anti-cultural" and "anti-artistic"; cultural policy-makers also regard comic books as "representative of Western culture". While comic strips, depending on the kind of magazines and newspapers in which they are published, address different age groups, the few comic books available in the Iranian market mostly appeal to children and young adults.

Compared to comics, manga have a much shorter history in Iran. They seem to have made their appearance in Iran around 2002 (Behjat, 2012) thanks to the activities of non-professional translators, the very type of people who continue to translate manga and make them available online today. While

\footnotetext{
${ }^{\mathrm{i}}$ Comic strip is a "series of drawings that read as a narrative, arranged together on the page of a newspaper, magazine, or book" while comic book refers to "bound collection of comic strips, usually in chronological sequence, typically telling a single story or a series of different stories" (The Britannica Concise Encyclopaedia pp. 437438).
} 
some Iranian manga such as Paradoxical and Ayyar are made available online by their Iranian creators for free, manga cannot be bought from the market in the country. To the best of our knowledge, no manga (foreign or local) has ever been officially published in Iran, because of the negative attitudes present toward comic books. The average age of Iranian manga readers, which is 21 (Ghorbanpour, 2017), implies that they mostly appeal to adult readers.

\subsection{Decision}

Our in-depth interviews with the founder and manager of AnimWorld revealed that similar to non-professional translation communities outside Iran, the decision-makers in Iranian non-professional translation communities are the translators themselves and not any overarching bodies imposing their tastes and preferences on what can be and how it should be translated. During the interviews we posed the following questions about decision-making in AnimWorld.

"Who is responsible for determining what titles can be translated by the non-professional translators who are active in the community?" The founder and manager of AnimWorld, Ghoghnuse, distinguished between three types of online translation communities working in different ways: communities of non-remunerated translators, partly-remunerated translators and those made of fully-remunerated translators. Moving from non-remunerated translators toward the fully-remunerated ones, the translators' freedom to choose the work for translation decreases. Asserting that AnimWorld is a free community in which no one is employed, the founder suggests that translators cannot be required to translate a specific title and not others. However, a competitive system was reported to be at work among translators over titles for translation. The time-honoured contributor-translators of the community can always impose their choices on the system, whereas other translators are said not to be completely free in deciding what to translate for the community. In this community a set of rules and procedures for obtaining points have been formulated under which the translators with the most points are free to choose whatever work they want to translate. The main source of obtaining points is the translators' speed in completing an assignment. This speed is measured by the time it takes a translator to submit their translation to the community after the original material is posted on the English source communities. And they may also lose points if they fail to meet a deadline; in turn this will affect their freedom of choosing their favorite works for translation.

"Who decides on the translation strategies adopted by the translators? Are there any preferred general strategies, namely a preference to translate literally or idiomatically?" The answer was that there were no predetermined translation strategies at work in the community. It was argued that given that the community translators are not employees, imposing guidelines on them would be disappointing and demotivating for them, and would consequently lead them to give up working on their projects or even leave the community.

The question "Who decides on the principles in translation production which may result in the community website's being blocked by the Internet Filtering Committee (Committee of Determining the Instances of Criminal Content) if they are not properly observed?" provided the following answer: "The Filtering Committee is not concerned with how we translate texts at all. The only things that they are sensitive to are the pictures and videos." Accordingly AnimWorld retouch some pictures or remove them completely. The ways such manipulations are performed are different from the way 
Iranian professional translators deal with visually "inappropriate" content. This is explained in Section 3.3.2

The founder added that since the majority of the community's readership is young adults and teenagers, AnimWorld would follow their self-made rules and moderate insults and swearwords. Other stricter rules laid down by the AnimWorld community were said to be at work which forbid translating words that are politically, religiously, ethnically or racially offensive. However, he also added that "all kinds of relationships among characters, all kinds of genres as well as violence in the contents are tolerated."

\subsection{Motivation}

In order to discover the motivations of the non-professional translators contributing to AnimWorld, we conducted an online survey. The questionnaire used was based on the one employed by McDonough Dolmaya (2012). She used a questionnaire to "explore, from a sociological perspective, how participants in crowdsourced translation initiatives perceive translation" (McDonough Dolmaya, 2012, p. 1). This perception was examined from various angles, one of which was the motivation of the translators to do an unremunerated translation for Wikipedia to their mother language.

To develop the items used in this questionnaire and adjust them to the purpose of investigating non-professional translators' motivations, we designed an online draft of the questionnaire, which we discussed with the manager of AnimWorld. As a result of these discussions, some items in the original questionnaire were edited and other items were added. To place the respondents, whose command of English varied, on the same footing, the questionnaire used was a Persian translation of the original questionnaire. All the subjects involved in the study were members of AnimWorld community; therefore, the questionnaire was made available online using Google Form. A hyperlink to the questionnaire was then posted on one of the community's online forums by the community manager. Twenty-nine translators of the nonprofessional community answered the questionnaire voluntarily. The respondents in the survey could account for their contributions by choosing from a list of intrinsic and extrinsic motivations which were randomly distributed throughout the questionnaire; they were not labeled so they could not be distinguished from each other. The respondents were asked to choose at least four options. Table 1 illustrates the questionnaire and an overview of the participants' motivations for their contributions. The figures must be interpreted cautiously because of the variations in the questions posed, and the methods used for the data collection. They can, at best, be considered only as indications of trends and should be taken as such.

In Table 1 items 1 to 11 focus on respondents' intrinsic motivations while the following ones deal with their extrinsic incentives. The most frequent intrinsic and extrinsic motivations reported by the respondents are shown in boldface. As far as intrinsic motivations were concerned, nearly two thirds of the respondents ( 65 percent) wanted to "provide other people with access to the content of manga and animes", with a similar percentage (62 percent) "doing the translation for fun". Equally common was "translating the source text due to enjoying spreading the culture of producing content for other people free of charge". The second most common intrinsic motivation among the fan translators was "practicing their English language skills" (55.1 percent) with "gaining more experience in translating manga and animes" and finding "translating the source text was intellectually stimulating" slightly below. 
Table 1. Motivation questionnaire

\begin{tabular}{|c|c|c|c|}
\hline & Reason & $\begin{array}{l}\text { No. of } \\
\text { respondents }\end{array}$ & Percentage \\
\hline 1 & $\begin{array}{l}\text { I did the translation to provide other } \\
\text { people with access to the content of the } \\
\text { manga. }\end{array}$ & 19 & 65 \\
\hline 2 & $\begin{array}{l}\text { I did the translation because of my interest } \\
\text { in the people of the source culture. }\end{array}$ & 11 & 37.9 \\
\hline 3 & $\begin{array}{l}\text { I did the translation to enjoy spreading } \\
\text { the culture of producing content for } \\
\text { other people free of charge just like } \\
\text { what happens in developed countries. }\end{array}$ & 18 & 62 \\
\hline 4 & $\begin{array}{l}\text { I did the translation to be a member of a } \\
\text { team of translators. }\end{array}$ & 10 & 34.4 \\
\hline 5 & $\begin{array}{l}\text { I did the translation to get more familiar } \\
\text { with translating manga. }\end{array}$ & 15 & 51.7 \\
\hline 6 & $\begin{array}{l}\text { I did the translation to practice my } \\
\text { English language skills. }\end{array}$ & 16 & 55.1 \\
\hline 7 & $\begin{array}{l}\text { I did the translation to practice my Persian } \\
\text { language skills. }\end{array}$ & 9 & 31 \\
\hline 8 & $\begin{array}{l}\text { Iid the translation to gain more } \\
\text { experience in translating manga and } \\
\text { animes. }\end{array}$ & 12 & 41.3 \\
\hline 9 & $\begin{array}{l}\text { Translating the source text was } \\
\text { intellectually stimulating to me. }\end{array}$ & 12 & 41.3 \\
\hline 10 & I did the translation for fun. & 18 & 62 \\
\hline 11 & $\begin{array}{l}\text { I did the translation because I was bored } \\
\text { and to fill my free time. }\end{array}$ & 7 & 24.1 \\
\hline 12 & I did the translation to attract clients. & 1 & 0.03 \\
\hline 13 & $\begin{array}{l}\text { I did the translation to enhance my } \\
\text { reputation as a translator }\end{array}$ & 4 & 13.7 \\
\hline 14 & $\begin{array}{l}\text { I did the translation to form a team with } \\
\text { other manga translators. }\end{array}$ & 3 & 10.3 \\
\hline 15 & $\begin{array}{l}\text { I did the translation to be able to participate } \\
\text { in the community's meetings. }\end{array}$ & 0 & 0 \\
\hline 16 & $\begin{array}{l}\text { My motivation was to enhance the general } \\
\text { culture of my country through introducing } \\
\text { the culture of the source text. }\end{array}$ & 8 & 27.5 \\
\hline 17 & $\begin{array}{l}\text { I did the translation to support the } \\
\text { community. }\end{array}$ & 12 & 41.3 \\
\hline 18 & $\begin{array}{l}\text { I did the translation to obtain a higher } \\
\text { status among the members of the } \\
\text { community. }\end{array}$ & 6 & 20.6 \\
\hline
\end{tabular}

And as for the extrinsic motivations of the non-professional translators, they were mostly in favor of translating to "support the community", whereas none of them translated with the aim of meeting the requirements of attending the community's real-world meetings. Contrary to the expectations of the community manager, who believed the most important incentive of the communities' translators was their "interest in the culture of the source text" as well as "enhancing the culture of the people in the target country", these two items comprise the least common motivations among the fan translators. Supporting the community mattered more to them than enhancing the general culture of their country through introducing the culture of the source text.

\subsection{Context}

\subsubsection{Textual factors}

Most of AnimWorld's products are manga translations. In this section, we shall first elaborate on the typical features of manga and subsequently 
illustrate the ways non-professional translators deal with them. It is noteworthy that, unlike those who translate Western comics, Iranian nonprofessional translators of manga are involved in the practice of indirect translation. Indirect or relay translation is the "the procedure whereby a text is not translated directly from an original ST, but via an intermediate translation in another language" (Shuttleworth \& Cowie, 1997). In fact, the manga produced in Iran are translations of English translations of Japanese originals made available online by scanslators- (scan + translators) who voluntarily translate Japanese manga and distribute them to other fans (Terpstra, 2012).

\subsubsection{Interaction between picture and text}

Due to the nature of manga, translators of this genre are faced with some particular elements which may not be of concern to the translators of other text types. They deal with messages that are embedded in various modes of communication interacting simultaneously. These interactions occur between texts and the pictorial elements surrounding them through what Saraceni (2003) terms "blending" and "collaborating". Blending occurs where messages are produced by the verbal and the visual elements merging in the same sign, and collaboration takes place where words and pictures "remain distinct from one another, but work together in order to convey meaning" (Saraceni, 2003, p. 27).

In a similar way, Martinec \& Salway (2005) argue that texts can expand on the visual mode when the relation between the two is not balanced. They observe three different relationships between text and image. The first one is elaboration, which occurs "if the same participants, processes and circumstances are depicted and referred to" by the text. The second relationship is extension, which takes place if by means of using a text "new but related things are referred to or depicted". And finally enhancement is the relationship between the image and the text "if related temporal, spatial or causal information is provided" by the text (p. 366).

In our analysis of the non-professional translations produced by AnimWorld, some of these relationships and interactions were found to pose challenges for the translators. An example was found in the translation of a panel from Miura (2003c): the panel shows the Count, who has just returned from a battle against the heretics, facing an "uncanny sight". Through extension the original panel depicts a large number of people "like a sea of flesh squirmed in a tangled mass" and among them is "the figure of a woman writhing in ecstasy contorting her face in pleasure"- the Count's wife. This is how the Count learns about his wife's infidelity- the woman who "he loved above all else". The Count, then, goes into "a blind rage" slaughtering everyone in the room except his wife. In a following panel, where some evil forces show the Count a review of his past life events, the woman's face is shown with the inscription "And seeing the triumphant knowing smile of your betrayer drove you to depth of despair" (p. 111). This extending description of the close-up image of the woman is the only sentence which reveals her inner feelings toward her husband and expands on the message conveyed by the image alone. The woman's smile is described as not signaling her remorse for what she has done but rather as indicative of her knowingly celebrating a victory. In the Persian translation, however, this expanding relationship between the words and the image has been distorted by describing her smile as "فرينده", which can literally be back-translated as "insincerely apologetic": the Persian reader is then given the impression that she is trying to coax her husband not to kill her. 
Here the translator has manipulated the text, i.e. exercised his agency by acting in a special manner to make the scene more palatable to the Iranian readers and more compliant with the norms expected by the Iranian society under such circumstances. This has been achieved by making the infidel spouse show remorse upon being caught in an incriminating situation, rather than presenting iconoclastic behaviors on the part of an infidel woman. In similar cases, the common practice in professional comic book translation in Iran would be to either totally delete the panel, add some sentences to show the woman's deep regret or to retouch the image so professionally that it would be impossible for readers to recognize what the original panel looked like. In this example, however, the expanding descriptions of remorse accompanying the victorious look on the woman's face make the panel confusing to readers.

\subsubsection{Interaction between image and sound (onomatopoeia)}

Onomatopoeia, an important feature of comic books, is used to provide a visual representation of the auditive dimension of events and emotions in writing (Kaindl, 1999). The way image-sound (onomatopoeia) interaction can affect a translator's agency can be illustrated by another panel from Miura (2003a). In this panel the elf is pleading the protagonist Guts urgently to do something to save one of its olds friends and in response Guts says "If you are so worried about it, why don't you save 'im?" (p. 35). In the English language version that served as the source text the onomatopoeia "GULP!" was used, which means "To swallow air audibly, as in nervousness" (American Heritage Dictionary, 2011). It extends the shock in the elf's face, which resulted from Guts' unexpected reply. This collaborating relationship has also been disrupted in the Persian translation as a result of the deletion strategy employed by the translator. The omission may be attributed to the lack of a corresponding onomatopoeic expression in Persian.

\subsubsection{Typographical features}

Typography describes a technique of changing the fonts of words in printed texts. Variations are used to indicate different meanings; for instance, hieroglyphics can be used to show that a character is Egyptian and old Germanic fonts to stand for Goths (Kaindl, 1999). Capital letters and boldface types are among the common typographical features found in comics. In manga published in the U.S it is a convention to employ capital letters rather than lowercase in dialogues; this means that in such texts capital letters do not imply a change in characters' voice or mood. Boldface types, however, are normally used to suggest loudness of voice of the characters (Forceville et al., 2010).

These typographical features present in the English source manga are rarely reflected in the Persian translations produced by AnimWorld community. In Miura (2003a), for instance, there is a panel in which the protagonist, who has just been arrested by the soldiers of the Mayor, is interrogated. In the source text the protagonist shouts "SCARE-CROWS" (p. 31), in capital letters and in boldface. These typographical features are not reflected in the Persian translation. The first feature cannot be rendered by an English-Persian translator as there is no capitalization in Persian. But the absence of boldface may make Persian readers fail to realize that a character is shouting and that he is very angry. The strategy of employing normal typography for shouting, for example, is due to the issue of space limit in translating from English into Persian, which is explained below. This 
limitation, however, may potentially affect non-professional translators' agency.

\subsubsection{Balloon shapes and space limit}

Balloons with the characters' spoken words and thoughts are the most important constituents of comics. However, the verbal elements inside a balloon are not the only ones to convey meaning. Balloons, also, create meaning by their sizes and shapes. The size and shape of a balloon are determined by the number of words characters utter and their feelings and moods (Forceville et al., 2010). As far as the size of balloons is concerned, the literature indicates that space limitation is a major issue for the translators of comic materials. Macková (2012) pointed that translators of comics do not have access to what he terms "the escapist solutions"; these solutions involve, for example, the addition of footnotes or lengthy explanations in order to properly convey the full meaning of the source text. These are not usually available to comic translators because the speech balloons do not offer room for such additions and when they are used, however scarcely, "they are seen as the violation of the original page composition requiring additional graphic adjustments" (Macková, 2012, p. 38). Grun \& Dollerup (2003) use the term constrained translation to refer to "translations that are, for practical or commercial reasons, spatially limited, such as, for instance, advertisements with brief and catchy slogans, cartoons, comics, and subtitles" (p. 198). However, footnotes and explanations are used in other countries when translating manga, both by professional and non-professional translators (see for example Zanettin, 2014).

This space constraint was observed in the analysis of the Persian nonprofessional translations under study. Expansion as a common strategy used in the English to Persian translation direction in general (Khajeh, 2003) was also observed in translation of manga as well. We identified two kinds of solutions that the translators used: typographical modification and displacement. Typographical modification was exercised through avoiding boldface types, reducing the font size in translations and using a more compact typographical style. These changes more often than not resulted in unreadable Persian texts and annulled the meaning-making role of the original's typographical features.

Displacement meant that translated utterances were placed in the balloons most convenient in terms of their space and location relative to the images they referred to. In other words, rather than placing translations in the same balloons as in the source text, translators (or editors) put them in other balloons which provided sufficient space for the translations and were at the same time close to the images they were to expand on.

This second strategy sometimes results in distortion in translations and reduction in meaning relative to the source text as this solution ignores the role of balloon shapes in message-creation. As Forceville et al. (2010) suggest, the shapes of balloons in a comic are not chosen arbitrarily: "angularity and asymmetry have more negative connotations than roundness and symmetry. Sharp, angular things are dangerous and potentially harmful, unlike rounded, smooth things" (Forceville et al., 2010, p. 69). This means that placing translations in balloons most convenient in terms of size and proximity to the utterer, without consideration of the functions of their shapes, can lead to inadequate renderings.

Such a displacement is found in the translation of a panel from Miura (2003b). In this panel, the Count's former physician is asking Guts to avenge him and his words are placed in a jagged contour balloon in the source text. 
This type of balloons encapsulates messages and utterances which are dangerous and potentially harmful, such as the source text's "AVENGE ME!" (p. 31). But a panel preceding it contains the word "PLEASE!" (p. 31), presented in a round balloon with smooth angles in the source text; in the Persian version this "please" is placed in the balloon with jagged contour of "AVENGE ME!" in the English version. The translation is further complicated by the Persian translator's use of his agency to dramatize by rendering "PLEASE!" as "بهت التماس ميكنم", literally "I beseech you." The result is a lack of harmony between the balloon shape, with its harsh, rough, and zigzagged pattern, and the humbleness of the words it contains, which may confuse Persian readers. This example illustrates how balloon shapes and space limitations can pose challenges to non-professional translators and discourage them from translating manga as a result.

\subsubsection{Reading direction}

Some textual factors may diminish a translator's motivation to render manga into Persian. However, the right-to-left reading orientation in Japanese manga makes translating them into Persian an easier task for translators compared with the translation of Western comics, since the Persian reading direction is the same as the Japanese one. Theisen (2011) believes that in translating comics when target languages have a different reading orientation from the source languages, interpretation and comprehension problems are very likely to occur among readers of the translations.

\subsubsection{Extratextual factors}

As mentioned above, copyright rules, commercialization and censorship are extratextual factors that affect the practices of Chinese fan translators (Zhang \& Mao, 2013). In Iran, only self-censorship influences the practices of fan translators. Copyright is not a concern for non-professional translators active in Iran since the country has not signed international copyright conventions. Instead, we found that community rules and a perceived higher freedom affect non-professional translators' agency in Iran.

\subsubsection{Constraining factor: Community rules}

The interview with the manager of AnimWorld shows that there are two general guidelines for translators contributing to this community. The first one concerns the way they render sensitive contents. It stipulates that the nonprofessional translators must not convey verbal or non-verbal references to political, religious, ethnical and racial issues. The second general guideline calls for discretion in translating contents of the source text that show or openly refer to nudity, violence, or sexual activity. This should be seen in view of the mostly teenage readership of the community. The rules governing the practices in AnimWorld are similar to the ones governing the practices of professional translators in Iran, but we found that fan translators applied them in interesting and different ways.

As for the first guideline, an example of the way non-professionals deal with sensitive content is the translation of a panel on Miura (2003c). Here the protagonist, Guts, says "sorry, I'm no good with priests" (p. 106). In the Persian translation دما زياد راحت نبستم" " " [I can't easily get along with other people] the word "priest" and the religious overtones were omitted. In another panel from Miura (2003c) Guts is characterized as having no faith in the Hereafter when he says, "Of course, once you die, that's it. Nothing comes after that. Nothing at all" (p. 114). In the corresponding Persian translation, 
"همه يه روزى ميميرن" [Sooner or later everyone dies], Persian readers hear nothing of the protagonist's lack of faith in life after death. Other examples of removing religious references in translation include "I'm not a heretic!", which is rendered as "من جادوكر نيستم" [I'm not a witch], "It is my sacred duty

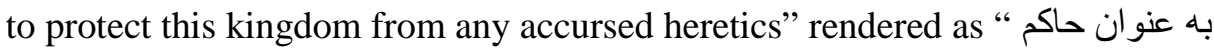
"وظيفه منه كه از مردم ربر ابر نيروهاى اهريمنى دفاع كنم " [It is my responsibility as the Mayor to protect people against the evil forces], in which the words "sacred" and "heretics" were omitted. In two separate panels from Miura (2003b) the religious references were suppressed by the rendition of the word "heretics" (p. 131 and p. 160) as " "كولى" in Persian. According to the Amid Persian Dictionary, the Persian equivalent means a shameless and impudent person, which has no associations relevant to the word "heretic", which means "a professed believer who maintains religious opinions contrary to those accepted by his or her church or rejects doctrines prescribed by that church" (Random House Webster's Unabridged Dictionary, 1997). Statements that are politically sensitive are also manipulated in translations. For instance, there is a statement in Miura (2003c) "In this town people are a thing to be feared" (p. 213), which refers to the mayor's being afraid of the power of the dissidents in the town. This statement was translated as “ وضع اين شهر به خاطر حضور شيطان

" [The town is in a sorry state because of the evil forces.] without any reference to the political conditions in the city. Non-professional translators' attempts to comply with the first guideline were most frequent when the source text contained swearwords. For example, the expression "crazy bastard" (p. 30) from a panel in Miura (2003a) was translated as " به نظر ميرسه " بروسه "تميدونه با كى طرفه " [Apparently he has no idea who he is dealing with!] and in numerous other instances curses are replaced with the expression "لعنتى" [Damn it!]- an expression that is not considered very offensive in Persian and yet reflects intense feelings.

The second guideline set down by AnimWorld concerns how community translators should tackle explicit content. In this case the non-professional translators were found to use strategies different from those adopted by Iranian professional translators: professional translators normally remove all references to explicit items in such a sophisticated manner that the readers do not detect the censorship, whereas the non-professionals usually gave their readers a clear, but oblique hint of what had been censored. In case of nudity, the strategy was very often that parts of the nude images were blurred, but the unretouched parts of the images as well as the words expanding on the images enabled readers to make informed guesses regarding the original content. A case in point is the translation of a panel from Miura (2003a) in which the protagonist is intimate with an evil creature transformed into a woman. In the Persian version, there are blurred spots all over the two characters' bodies, except for their hands and heads, but their expressions and positions as well as the dialogues reveal the nature of the scene.

In dealing with violence, however, the community employs a different strategy. Violent images were not blurred or retouched but the speeches expanding on them were either omitted or moderated. In the translation of the English utterance "I'm going to eat you alive boooy!!" (p. 70) from Miura (2003b), images were retained intact, but the word "alive" was omitted and the long and scary-sounding "boooy" was translated as a normal word in an attempt to diminish the vehemence of the threat. In addition to the verbal messages of the source texts, onomatopoetic expressions were also modified. For example, there is a panel in Miura (2003b) in which a monster is drinking 
blood. Next to its mouth is the uppercased onomatopoetic expression "SLURP" (p. 60). This onomatopoeia, which implies drinking or eating noisily (American Heritage Dictionary, 2011), was translated as "ha ha ha" in Persian, probably in an attempt to reduce the violence of the scene. In the English version the monster is savoring the blood of its prey, whereas in the Persian version the monster laughs aloud with a closed mouth. Another example is found in the panel from Miura (2003b, p. 157) in which the sentence "I'll skewer your damned head on my blade of steel!" is translated as "تو رو با همين فو لاد ضخيم شكستت ميدم." [I'll beat you with this thick steel blade of mine!], which totally removes the brutality of the source text. Such adherence to community rules constrains translators' agency because the verbal messages in translations do not match the images that the texts are intended to expand on, which can in turn result in inadequate translations.

\subsubsection{Boosting factors}

In contrast to the community rules which control non-professional translators' practices and can potentially limit their willingness and ability to translate, we identified some extra-textual factors that encouraged their agency. The more freedom available to the translators active in the cyberspace was found to increase their willingness as well as their power to translate. This freedom, which is partly due to the use of aliases rather than their real names, was most obvious in the translations of some source elements which are forbidden in professional translations in Iran as well as in the language register used in the translations.

In the translation of taboos such as references to love, affection, wine, drunkenness, and bars professional translators need to use caution if they do not want their works to undergo censorship (Rajabzadeh 2001). However, non-professional translators rendered almost all of these items directly or with little modifications. On a panel from Miura (2003a), for instance, Guts tells the elf "You are from the tavern" (p. 42), which was translated into Persian without any modifications as "تو از اون ميخونه اي". Another example is in the translation of "It's homemade wine. It'll warm you up". Unlike what is the norm in professional Iranian translation, the reference to wine was literally transferred in the Persian version.

The below examples of language register used by non-professionals reveal there is a noticeable difference between online fan-translated manga and officially published comic books in Iran. Non-professionals translate texts in a way that appeals to their average readers, mostly Iranian teenagers, and therefore they use words and expressions that are typical of the language of teenagers rather than those which are deemed to be appropriate or correct according to the norms and conventions in professional translation practice. In Miura (2003a) there is a panel where the elf is trying to talk Guts out of stepping out in the rain by saying "The rain's pretty heavy" (p. 105). The Persian translation is very colloquial: "حال نميده كه نو اين بارون راه برى" [It's no fun to walk in the rain], which is very frequent among teenagers but does not comply with the norms prevalent in professional translation. In another panel a priest says to Guts: "Don't worry my friend. I have God on my side". Although this sentence does not sound colloquial in English, the tone is very informal in the Persian manga rendition: "بيخيال.خدا با ماست" [Come on! God is just around!]. 


\section{A proposed model}

Drawing on the model proposed by Haddadian-Moghadam (2014) for the analysis of agency in professional translation, we have developed a framework for the study of agency in non-professional manga translation. This framework summarizes the findings in the present study. It employs the three main levels of decision, motivation and context identified by Haddadian-Moghadam (2014), with different subcategories particular to non-professional manga translation. This model can be further developed to account for phenomena in non-professional translation in general by including such extra-textual factors as civic responsibility and activist agendas on the part of both translators and community managers. The part dealing with the agency of community managers can be a subject for another study.

Table 2. A proposed model for the study of agency in non-professional translation

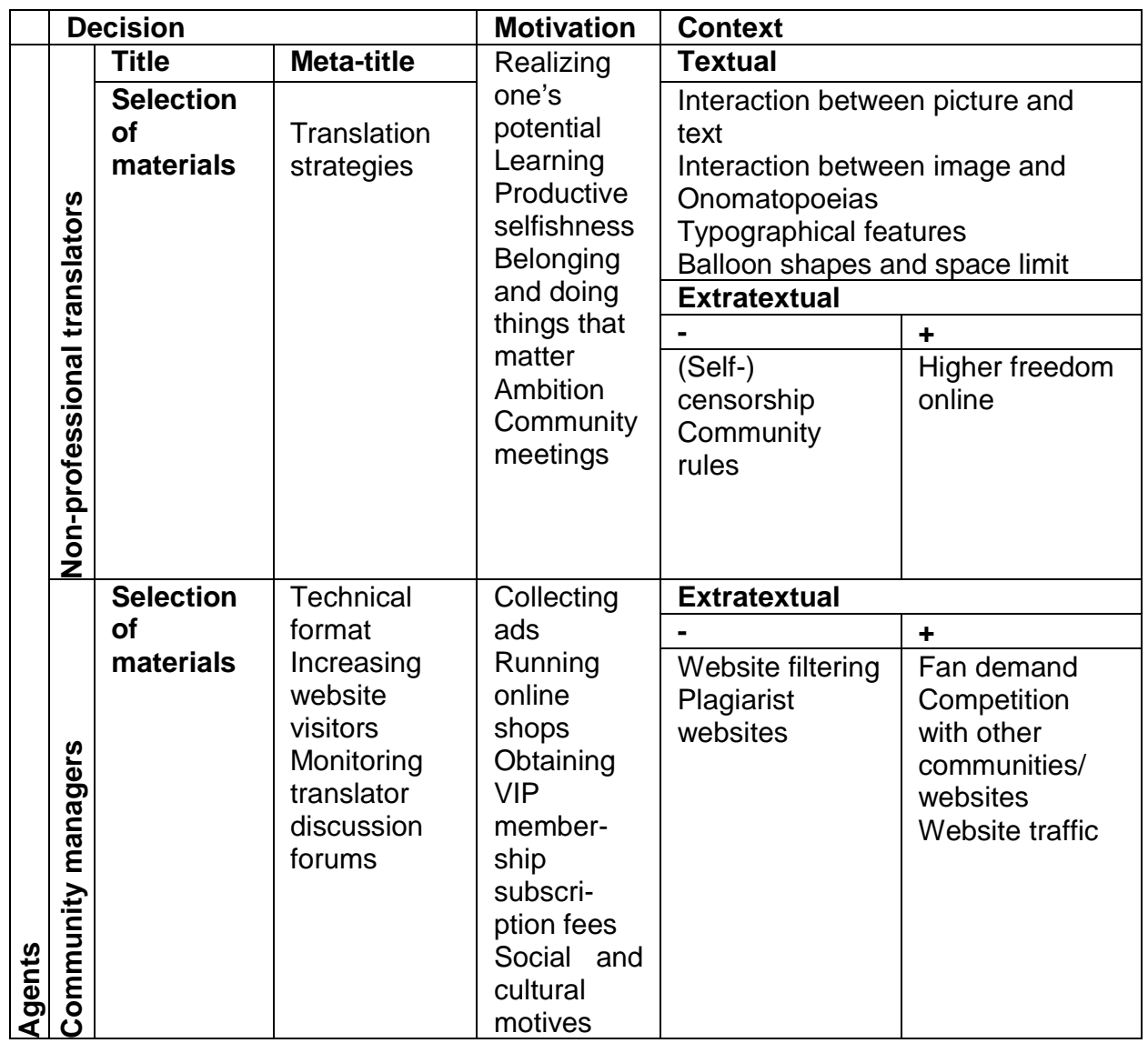

\section{Conclusion}

\subsection{Decision}

In the non-professional translation community under study, the titles for translation were selected by the fan-translators themselves. However, there are limits to the freedom of selecting their favorite titles. With the exception of time-honored translators, others can only choose a title for translation if no other translator with a higher number of points has decided to work on a 
recently published source item. These source texts are not selected based on suggestions by the community manager or other third parties. In professional translation in Iran translators usually have to consider the publishers' suggestions and do not always translate their favorite works. Therefore, unlike professional translators, non-professional one exercise agency at the level of selection of works for translation in Iran.

\subsection{Motivation}

Intrinsic motivations were the most often cited ones by the fan translators under study. Respondents were prompted less by opportunities to attract clients and to enhance their reputation as translators and more by intrinsic motivations such as to provide other people with access to the content of the manga or animes and to enjoy spreading the culture of producing content for other people free of charge. They also did the translations more for fun than because of their interest in the culture and people of the source text. And supporting the community was more important to them than enhancing the general culture of their country by introducing the source text culture.

\subsection{Context}

Considering the textual factors that affect non-professional translators' agency, all of the identified factors, except for one, constrained their willingness and ability to translate. However, among the extratextual factors identified, namely community rules and higher freedom in the cyberspace, the former acted as constraining fan translators' agency while the latter acted as a booster.

Worth noting is the difference between the strategies fan translators employ to overcome the forces constraining their agency and those used by professional translators. As suggested by Haddadian-Moghadam (2014), Iranian professional translators try not to be "voiceless" in the face of the constraints, namely the state policies concerning the translation of books, by challenging them. One strategy they adopt to challenge such powers is to "use punctuation marks to mark missing parts in the text, and often publicly talk about censorship in their interviews" (Haddadian-Moghadam, 2014, p. 173). By contrast, fan translators find themselves enforcing community rules laid down by consent of fan translators themselves with the aim of preventing the community website from being blocked by the Filtering Committee. They find this Committee mostly sensitive to visually explicit contents, so they try not to include them in their translations provided that the reading experience is not diminished substantially. In other words, as the translation products of the community clearly show, they try to strike a balance between removing the important elements in stories and overtly challenging the Filtering Committee. They have not always been successful at maintaining this balance, since at the time of writing these lines, the community website has been blocked by the Committee. 


\section{References}

Akiyama, T. (1990). Japanese painting. New York: Rizzoli International Publications. American Heritage dictionary of the English language ( $5^{\text {th }}$ edition). (2011). Boston: Houghton Mifflin Harcourt.

Amid, H. (1975). The Amid Persian dictionary. Tehran: Amir Kabir Publications.

Behjat, S. (2012). Manga and its social effects. Anthropology and Culture. Retrieved from http://anthropology.ir/article/30782.html

Encyclopaedia Britannica (2006). Britannica concise encyclopedia. London: Encyclopaedia Britannica Ltd.

Cha, K. (2007). Kodansha launches second manga contest. Publishers Weekly. Retrieved from https://www.publishersweekly.com/pw/by-topic/new-titles/adultannouncements/article/2575-kodansha-launches-second-manga-contest.html

Chen, A. (2014, December 06). China cracks down on unofficial fan groups who subtitle hit American TV shows. Retrieved from http://www.scmp.com/news/ china/article/1656544/china-cracks-down-unofficial-fan-groups-who-subtitle-hitamerican-tv

Chesterman, A. (2017): Literary translation in modern Iran: A sociological study. Iranian Studies, 50(4), 638-642.

Díaz-Cintas, J. \& Muñoz Sánchez, P. (2006). Fansubs: Audiovisual translation in an amateur environment. Jostrans: The Journal of Specialised Translation. 14(6), 37-52. Retrieved from http://www.jostrans.org/issue06/art_diaz_munoz.php

Dwyer, T. (2012). Fansub dreaming on ViKi. The Translator, 18(2), 217-243. doi: 10.1080/13556509.2012.10799509

Emami, K. (2000). "Naqsh-e nasheran dar oft-o-va khiz-e tarjomeh-ye adabi [The role of publishers in the rise and fall of literary translation]." In Majmu'eh-ye Maqalat-e Nokhostin Hamayesh-e Tarjomeh-ye Adabi dar Iran [The proceedings of the first literary translationconference in Iran], ed. by Ali Khazaeefar. 45-56. Mashhad: Banafsheh.

Forceville, C. \& Veale, T. \& Feyaerts, K. (2010). Balloonics: The visuals of balloons in comics. In G. Joyce \& D. Hassler-Forest. (Eds.), The rise and reason of comics and graphic literature: Critical essays on the form. Jefferson: McFarland.

Gharibpour, K. (2016, July 15). An investigation into the status of comic strips in Iran. Retrieved from http://www.ibna.ir/getdf50xjyt0sk6.2a2y.html

Ghorbanpour, E. (2017, April 2). Reading the lines of imagination. Retrieved from http://40cheragh.org/\%d8\%af\%d8\%b1-\%d8\%ad\%d8\%a7\%d9\%84-\%d8\%ae\% d9\%88\%d8\%a7\%d9\%86\%d8\%af\%d9\%86-\%d8\%ae\%d8\%b7-\%d8\%ae\%db\%8c $\% \mathrm{~d} 8 \% \mathrm{a} 7 \% \mathrm{~d} 9 \% 84 /$

Grun, M. \& Dollerup, C. (2003). 'Loss' and 'gain' in comics, Perspectives: Studies in Translatology, 11(3), 197-216

Haddadian-Moghadam, E. (2014). Literary translation in modern Iran: A sociological study. Amsterdam: John Benjamins

Howe, J. (2008). Crowdsourcing: How the power of the crowd is driving the future of business. London: Random House.

Jenkins, H. (2009). Confronting the challenges of participatory culture: Media education for the $21^{\text {st }}$ century. Cambridge: MIT Press.

Johnson-Woods, T. (2010). Manga: An anthology of global and cultural perspectives. New York: Continuum.

Jüngst, H.E. (2008). Translating manga. In F. Zanettin (Ed.), Comics in translation. (pp. 50-88). Manchester: St. Jerome Publishing

Kaindl, K. (1999). Thump, whizz, poom: A framework for the study of comics under translation. Target. 11(2), 263-288.

Kenevisi, M. S. \& Sanatifar, M. S. (2016). Comics polysystem in Iran: A case study of the Persian translations of Les Aventures de Tintin. TranscUlturAl: A Journal of Translation and Cultural Studies. 8(2), 174-204. Retrieved from https://journals. library.ualberta.ca/tc/index.php/TC/article/view/28560/20930 
Khajeh, Z. (2003). The rendering of English idiomatic expressions into Persian: English dramas and their corresponding translations in contrast. (MA thesis). Shiraz: Shiraz Islamic Azad University.

Kinnunen, T. \& Koskinen ,K. (2010). Introduction. In T. Kinnunen \& K. Koskinen (Eds.), Translators' agency (pp. 4-10). Tampere: Tampere University Press.

Macková, M. (2012). Specifics of comics translation (MA thesis). Retrieved from http://is.muni.cz/th/215574/ff_m/specifics_of_comics_translation-diploma mackova.pdf

Martinec, R. \& Salway, A. (2005). A system for image-text relations in new (and old) media. Visual Communication, 4(3), 337-371.

McDonough Dolmaya, J. (2012). Analyzing the crowdsourcing model and its impact on public perceptions of translation. The Translator, 18(2), 167-191.

Mesipuu, M. (2012). Translation crowdsourcing and user-translator motivation at Facebook and Skype. Translation Spaces, 1(1), 33-53.

Miura, K. (2003a). Berserk: The black swordsman. Retrieved from http://mangatraders.biz/series/Berserk

Miura, K. (2003b). Berserk: The brand. Retrieved from http://mangatraders.biz/series/ Berserk

Miura, K. (2003c). Berserk: The guardians of desire. Retrieved from http:// mangatraders.biz/series/Berserk

Pérez-González, L. \& Susam-Sarajeva, S. (2012). Non-professionals translating and interpreting: Participatory and engaged perspectives. The Translator, 18(2), 149165.

Rad, S. (1976). Rostam va Esfandiyar, Illustrated by Sirous Rad. Tehran: Kanoon-e Parvaresh-e Fekri Koodak va Nowjavan.

Rahimi, M. Z. (2015). Ideologically driven strategies in the translation of comics before and after the islamic revolution. International Journal of English Language \& Translation Studies. 3(4), 42-49.

Rahimzadeh, M. (2000). "Interview.” Motarjem. 9(32), 32-40.

Rajabzadeh, A. (2001). Momayyezi-ye ketab: Pazhuheshi dar 1400 sanad-e momayyezi- ye ketab dar sal-e 1375 [The censorship of books: A study of 1,400 censor files in 1996]. Tehran: Kavir.

Random House Webster's unabridged dictionary. (1997). New York: Random House Reference.

Saraceni, M. (2003). The language of comics. New York, NY: Routledge.

Shuttleworth, M. \& Cowie M. (1997). Dictionary of translation studies. Manchester: St. Jerome.

Tarhandeh, S. (2011). Striving to survive: Comic strips in Iran. Bookbird: A Journal of International Children's Literature, 49(4), 24-31.

Terpstra, K.A. (2012). Spreading the word: fan translations of manga in a global context (PhD thesis). Retrieved from https://ir.uiowa.edu/cgi/viewcontent.cgi ?article $=3368 \&$ context $=$ etd

Theisen, N. (2011). Declassicizing the classical in Japanese comics. In G. Kovacs \& Marshall C. W. (Eds.), Classics and comics, (pp.59-72). New York: Oxford University Press.

Zanettin, F. (2014). Visual adaptation in translated comics. inTRAlinea: Online

Translation Journal, 16(1). Retrived from http://www.intralinea.org/archive/article/ 2079

Zhang, W. \& Mao, C. (2013). Fan activism sustained and challenged: participatory culture in Chinese online translation communities. Chinese Journal of Communication, 6(1), 45-61. 